Dirección Clara Martínez Cantón Gimena del Rio Riande Ernesto Priani

Secretaría Romina De León

RHD 4 (2019)

BIBLIOTECA NACIONAL DE COLOMBIA. Mapeando Colombia: la construcción del territorio, 2018.

\title{
http://bibliotecanacional.gov.co/es-co/colecciones/biblioteca- digital/mapoteca\#
}

Reseña realizada por:

Stephanie Carolina SARMIENTO ROJAS

Universidad Pablo de Olavide sarmientorojas5@gmail.com

Desde comienzos de esta década, América Latina se ha integrado de manera gradual en el panorama de las Humanidades Digitales (HD), un campo que ha sido trabajado, predominantemente, desde el norte global. Esa incursión ha respondido a diferentes ritmos, $y$ es posible evidenciar varios logros en ese camino. En lo que se refiere al caso colombiano podríamos decir que, aunque su incursión ha sido más reciente con respecto a otros países de la región, como México o Argentina, Colombia ha dado pasos firmes en los dos últimos años.

El propósito de este texto es estudiar la experiencia colombiana en las HD, por medio de la Mapoteca digital ${ }^{1}$ y el libro Mapeando Colombia: la construcción del territorio2, ambos proyectos producidos por la Biblioteca Nacional de Colombia (BNC). Antes de entrar en materia, haré un breve repaso sobre los aportes colombianos a las $H D$, para, luego, a través de los dos proyectos delinear tensiones a las que se pueden enfrentar iniciativas de este tipo y señalar aciertos y retos.

Pese a que Colombia no hizo parte de los primeros países latinoamericanos en introducirse en las HD, si fue el primer país de la región en ofrecer un programa de maestría en este tema, el cual es impartido por la Universidad los Andes. Desde que inició en 2017, la oferta ha estado activa sin interrupciones y ya cuenta con egresados.

1 Accesible desde: https://bit.ly/2yyLuWw.

2 Accesible desde: https://bit.ly/2HnHFIA. 
La Universidad de Caldas es otra institución que ha estado trabajando en la creación de su propia maestría en colaboración con la Universidad Paul Valéry y la Universidad de Piura 3. Así mismo, como parte del proceso de fortalecimiento de la comunidad interesada en las HD en Colombia se han creado espacios de diálogo y discusión por medio de la Red Colombiana de $\mathrm{HD}^{4}$ y eventos como la Semana del Libro y la Lectura Digital ${ }^{5}$, la cual cuenta ya con cuatro versiones. Esta última iniciativa ha sido liderada por la BNC. De igual modo, la Universidad Nacional de Colombia y la Universidad Jorge Tadeo Lozano han abierto espacios de experimentación por medio del Laboratorio de Cartografía Histórica e Historia Digitalo (CaHID) y TadeoLAB7, respectivamente. Por su parte, el Ministerio de Cultura ha destinado fuentes de financiación para impulsar la creación de proyectos e investigaciones por medio de la convocatoria Crea Digital $^{8}$ y diversos estímulos a través de la BNC 9 . Por último, no podríamos dejar por fuera el reconocimiento obtenido por la Biblioteca Digital de la Biblioteca Luis Ángel Arango en los DH Awards ${ }^{10}$, al ser ganadora en la categoría Best use of DH for Fun con el Cancionero escolar ${ }^{11}$, y en la categoría Best use of $D H$ for Public Engagement con el proyecto Imágenes y relatos de un viaje a América ${ }^{12}$.

En este camino también podríamos mencionar la realización de diversos proyectos desarrollados desde la BNC que han oscilado en el ámbito de las HD. Uno de los más recientes es Mapeando Colombia: la construcción del territorio, un libro digital derivado de la Mapoteca. Este último es un repositorio de acceso abierto creado en el 2011 que contiene aproximadamente 1.700 documentos cartográficos, de Colombia, el continente latinoamericano y otras latitudes del mundo, desde el periodo colonial hasta el siglo XX. Su equipo de trabajo cuenta con profesionales en geografía, historia, topografía, bibliotecología, diseño, antropología, ciencias de la tecnología y la información. Como parte de su misión patrimonial, la BNC se ha encargado de centralizar, digitalizar, vectorizar y georreferenciar estas fuentes, velar por su conservación y, por medio, de la Mapoteca Digital proporcionar herramientas para el acceso y difusión al público interesado. Según Anthony Picón ${ }^{13}$, miembro del proyecto, el problema principal que solventó la digitalización de la documentación fue el acceso a estas fuentes que eran poco consultadas, dado que, por ejemplo, en los programas universitarios de ciencias sociales y humanas los mapas no eran una fuente de investigación social tan valorada,

3 La Universidad de Caldas busca consolidar Maestría en HD, véase: https://goo.gl/TZzl gQ.

4 Accesible desde: http://www.rehdi.co/.

5 Este fue el programa de la última versión: https://goo.gl/zsYMhJ.

6 Accesible desde: http://www.humanas.unal.edu.co/cahid/.

7 Accesible desde: https://www.utadeo.edu.co/es/micrositio/tadeolab.

8 Accesible desde: https://bit.ly/2FrA6ht.

9 Véase las becas de estímulos desde: https://bit.ly/2MkswOR.

10 Accesible desde: http://dhawards.org/.

11 Accesible desde: http://www.banrepcultural.org/cancionero.

12 Accesible desde: http://www.banrep.gov.co/impresiones-de-un-viaje.

13 A. Picón (comunicación personal, 24 de mayo de 2018). 
con respecto a otros tipos de fuentes. En consecuencia, la Mapoteca ha logrado hacer un llamado de atención sobre esta documentación.

Así, el corpus documental de este proyecto se ha ido conformado a través del material que reposa en diferentes instituciones. Entre ellas, entidades nacionales y locales como el Archivo General de la Nación, la Universidad Nacional sede Bogotá y Medellín, el Instituto Geográfico Agustín Codazzi, la Sociedad Geográfica de Colombia, el Museo Nacional, el Museo Bogotá; donaciones de coleccionistas privados, quienes han accedido a abrir sus colecciones al público por medio de este proyecto, aligerando las restricciones para consultarlas; $y$ entidades que por falta de las infraestructuras adecuadas no pueden digitalizar su material. De igual modo, la Biblioteca Nacional de Portugal ha participado cediendo colecciones digitalizadas sobre Colombia. En esta medida, la Mapoteca no es un proyecto cerrado. Constantemente, está recibiendo documentación y está a la espera de poder integrar, aparte de Bogotá y Medellín, más ciudades del país. La difusión de este proyecto también ha sido significativa gracias a la alianza que cuenta con Old Maps Online ${ }^{14}$. Esta Mapoteca es la única en América Latina en sostener un acuerdo con ese repositorio internacional.

Es de destacar, también, como indica Picón (2018), el trabajo mancomunado que convergió en este proyecto entre el área de Colecciones y Servicios y Desarrollos y Humanidades Digitales que se refleja en dos aspectos. El primero, la Mapoteca contó con una reedición en 2017 en la que se realizaron grupos focales para afinar la información ofrecida por el repositorio y se creó una nueva ventana de visualización que ha hecho más amigable la búsqueda del material cartográfico.

En segundo lugar, aparte de la utilización de las fuentes dispuestas por este repositorio como materia prima para investigadores sociales, en 2017 comenzó el proceso de creación del libro digital Mapeando Colombia: la construcción del territorio. Un libro digital que editó la BNC en conjunto con profesionales en disciplinas de la geografía e historia de la Universidad de los Andes y la Universidad Nacional de Colombia, y que salió a la luz a través de entregas mensuales. Este libro aprovecha los medios digitales para analizar los diferentes mapas que han construido el territorio colombiano, desde temáticas como cartografía y publicidad, cartografía y arte, encuentros culturales, proyectos de reconocimiento territorial, entre otros. De este modo, Mapeando Colombia convoca a públicos más amplios a través de los recursos multimedia que dispone, el lenguaje empleado y las diversas miradas al material cartográfico de la Mapoteca desde este formato. Lo cual permitirá que este producto sea utilizado como material pedagógico en educación secundaria y universitaria.

Como se puede ver los autores de estos proyectos tienen un interés especial en poder caracterizar el público interesado en la geografía e historia, para este objetivo se han servido de metodologías como el design thinking y el desarrollo de habilidades como la empatía digital

14 Accesible desde: http://www.oldmapsonline.org/. 
para propiciar esos encuentros; herramientas que resultan ser provechosas para profesiones en humanidades que no cuentan con formación en alcanzar públicos amplios ni en la caracterización del mismo. En este sentido, resulta ser un acierto el lugar que ocupa esta caracterización en los dos proyectos, puesto que nos permite estudiar hasta qué punto la "promesa de democratización del conocimiento" en las HD, como la denomina Aurelio Meza (2017), es viable en la región.

En esta línea, la crítica de Frederick Cooper sobre el concepto de globalización resulta ser pertinente para el campo de las HD. Para Cooper, la World Wide Web ha creado una ilusión de conexión que se sustenta en la idea de la posibilidad de entablar enlaces desde cualquier lugar del mundo a través de la red, un hecho que podría terminar por convertirse en "un modelo para todas las formas de comunicación global" (2002, p. 12). Sin embargo, este historiador afirma que la "integración creciente y a escala planetaria" (p. 22), mediante la red ha invisibilizado realidades particulares de aquellos quienes no han logrado hacer parte de ese aparente sistema único de conexión global de nuestra época. Es decir, la desconexión de ciertas localidades dentro de este sistema oscurece la posibilidad no solo de entablar otro tipo de conexiones; sino que, además es irreflexiva con respecto a las condiciones que no permiten tal conexión.

Aterrizando esta crítica a las HD, es conveniente traer a colación la opinión de Aurelio Meza, integrante del proyecto Poética Sonora ${ }^{15}$. Meza afirma que el despliegue en aumento de las TIC's, la aparente gratuidad de contenidos y el acceso abierto "enfocado en la reducción de restricciones para acceder a conocimientos" (2017, p. 112), han creado una ilusión similar en el campo HD. Meza aboga por la necesidad de además de caracterizar las audiencias de los proyectos de HD, tomar conciencia del público que realmente cuenta con las condiciones para acceder a un producto digital. A partir del caso mexicano, Meza muestra cifras de la reducida población que tiene acceso a un computador propio o a conexión de internet, una situación que puede trasladarse a varios países de la región. Adicionalmente, contar con el cubrimiento de estas necesidades tampoco garantiza la difusión o acercamiento a toda la población de un proyecto de HD, pues la alfabetización digital requiere de tiempo y estrategias para hacer un uso activo de los conocimientos con un sentido social o político.

Por consiguiente, el interés por afinar las herramientas para generar conexiones más sustanciales, teniendo en cuenta las desigualdades estructurales a las que se enfrentan productores y receptores del conocimiento es determinante dentro del contexto latinoamericano. Sin embargo, Mapeando Colombia genera un interrogante en lo referente al tipo de lectura que propone. Una diferencia que han supuesto los medios digitales con respecto a los medios análogos ha sido la difuminación de las líneas divisorias que distinguen entre un formato y otro. Es decir, mientras que de manera análoga resulta ser evidente la diferencia entre una carta de

${ }^{15}$ Accesible desde: https://poeticasonora.mx/. 
un menú, un libro de un periódico; en la era digital las diferencias no son tan perceptibles en la medida en que las diversas expresiones se manifiestan en un mismo aparato y tienen la misma forma (Pons, 2017). Es por esto que un producto de conocimiento denominado libro digital, como es este el caso, lleva al lector a preguntarse qué tipo de lectura diferente a la análoga se está proponiendo.

Además de hacer un buen uso de herramientas multimedia, la reflexión sobre el medio digital en el que se estudian fenómenos humanísticos debe ser visible, pues de lo contrario se desaprovecha la posibilidad de presentar otro tipo de lectura o visualización desde el mundo digital. En este caso, aunque los mapas están presentes en cada uno de los capítulos, estos no ocupan un lugar dentro de la narrativa. Es decir, no es perceptible qué tipo de lecturas pueden darse a este tipo de fuentes primarias desde un medio digital, ya que el autor solo contextualiza el entorno social en el que fue producido el mapa y remite al lector a visualizarlo.

Por eso, Mapeando Colombia nos enfrenta a la diferenciación que estableció Anaclet Pons (2017) entre Humanidades en la era digital y Humanidades Digitales. El primer concepto se refiere al mero uso de herramientas pertenecientes a la tecnología digital, mientras que el segundo además de trabajar permanentemente con ellas, propone o reflexiona sobre nuevos modelos para crear conocimiento. Aunque Mapeando Colombia invierte una buena cantidad de recursos en atraer y caracterizar un público determinado y hacer inteligible el contenido, lo cual resulta ser un acto inusual en una academia tradicional como la colombiana, este proyecto encajaría de forma más adecuada en el concepto de Humanidades en la era digital. Una etapa en la que se evidencian mejoras del proyecto madre, pero con nuevos aspectos por trabajar que muestran el proceso natural de experimentación y conocimiento del medio.

\section{REFERENCIAS BIBLIOGRÁFICAS}

Cooper, F. (2002). ¿Para qué sirve la globalización? La perspectiva de un historiador africanista. Nova África, 10, 7-33.

Meza, A. (2017). Decolonizar las Humanidades Digitales: cómo diseñar un repositorio digital de sur a norte. Intervenciones en estudios culturales, 4, 109-131. Recuperado de https://bit.ly/2f9WTnz el 04/07/2019.

Pons, A. (2017, junio 14). Historia Digital. Conversatorio en Humanidades Digitales [Video]. Recuperado de https://goo.gl/bZBQxk el 04/07/2019. 